\title{
Clinical effectiveness of currently available low-vision devices in glaucoma patients with moderate-to-severe vision loss
}

This article was published in the following Dove Press journal:

Clinical Ophthalmology

10 April 2017

Number of times this article has been viewed

Yogesh Patodia'

Elizabeth Golesic ${ }^{2}$

Alex Mao ${ }^{2}$

Cindy ML Hutnik ${ }^{2}$

'Department of Medicine, Ross University, Iselin, NJ, USA;

${ }^{2}$ Department of Ophthalmology, University of Western Ontario,

London, ON, Canada
Correspondence: Cindy ML Hutnik Department of Ophthalmology, University of Western Ontario, 268 Grosvenor Street, London, ON N6A 4V2, Canada Tel + I 5196466100 (ext 66272) Email cindy.hutnik@sjhc.london.on.ca
Purpose: The aim of this trial is to study the effectiveness of currently available low-vision devices in glaucoma patients with moderate-to-severe vision loss.

Design: This is a randomized pilot clinical trial.

Participants: Sixteen low-vision glaucoma patients participated in this study.

Methods: Patients with a best-corrected visual acuity between 20/70 and 20/400 in the better eye and a diagnosis of stable primary or secondary open-angle glaucoma were randomized to a low-vision treatment group or a nonintervention control group. A telephone interview was conducted before and after the 4-week testing period to assess functional vision. Patients placed in the treatment group received a low-vision examination and used various currently available low-vision aids. Patients placed in the control group received a low-vision examination only. Changes in patients' reading ability and overall visual ability were chosen as the primary outcomes. Other visual functioning domains (mobility, visual information processing and visual motor skills) were considered as secondary outcomes.

Results: Ten patients in the treatment group showed a significant improvement in reading ability and overall visual ability compared to the control group. The difference in mean score for reading ability was 2.52 logits $(2.02 ; P<0.05)$ and overall visual ability was 0.78 logits $(0.64 ; P<0.05)$. However, no significant improvement was noted in the other visual functioning domains involving mobility and visual motor skills.

Conclusion: Currently available low-vision devices primarily enhance central vision with limited benefits to functional activities relying on peripheral vision.

Keywords: low vision, glaucoma, quality of life, activities of daily living

\section{Introduction}

Visual impairment ranks among the ten most prevalent causes of disability in North America. ${ }^{1}$ Age is a major risk factor for the leading causes of low vision which include age-related macular degeneration (ARMD), glaucoma, diabetic retinopathy and optic neuropathies. ${ }^{1}$ Of these, irreversible vision loss is most commonly caused by ARMD and glaucoma, diseases for which there exists no cure. ${ }^{2}$ Quality of life and functional ability are negatively impacted by vision loss and blindness. ${ }^{2}$ Loss of visual ability impairs both mental and physical functioning, limiting activities of daily living (ADLs) (eating, dressing, reading, writing, mobilizing, interpersonal communication, etc). ${ }^{3}$ Impedance on basic functioning secondary to visual impairment can lead to loss of independence, low self-esteem or depression. ${ }^{3}$ When pharmacological or surgical interventions prove futile in advanced vision loss, low-vision rehabilitation may be the only option for improving functional vision in patients. The goal of low-vision 
rehabilitation is to not restore lost vision but rather utilize the remaining vision to its fullest potential, thus enabling patients to reclaim their ADLs and thereby their independence and optimized quality of life.

Our study is based on the Veterans Affairs Low Vision Intervention Trial (LOVIT) which was a randomized controlled trial involving patients with low vision secondary to ARMD. ${ }^{4-6}$ The trial's goal was to evaluate the efficacy of an outpatient low-vision rehabilitation program for patients with moderate-to-severe vision loss. The trial's intervention was effective in improving all aspects of visual function when compared with the control group. Despite this success, there have been very few studies to examine the effectiveness of low-vision rehabilitation in patients with chronic, irreversible visual loss secondary to glaucoma. To date, no randomized trials have been conducted. It is not possible to extrapolate the findings and recommendations of the LOVIT ARMD study to glaucoma patients because of differences in the nature and pattern of visual loss between the two diseases. However, the ARMD experience has established a proof of principle that can be developed in a glaucoma protocol design.

In patients with advanced glaucomatous optic neuropathy, functional loss is often observed with mobility issues and difficulty ambulating. ${ }^{7}$ In one study, patients with visual field loss secondary to their glaucoma showed a diminished traffic gap judgment when crossing the street, which leads to an increased risk of harm. As a whole, the group made $23 \%$ more errors in identifying a gap as crossable when the gap was too narrow to be made safely. ${ }^{7}$ Another study found that $25 \%$ of patients with visual field loss in both the eyes reported a moderate-to-severe restriction in their mobility activities overall. ${ }^{8}$ Field loss secondary to glaucoma has also been shown to lead to a lower vision-related quality of life score. ${ }^{9}$ When examined collectively, these reports and others suggest that individuals with reduced visual fields and glaucoma experience more falls, more motor vehicle accidents, greater overall difficulty with mobility activities and an overall decreased quality of living. ${ }^{7}$ Best-corrected central visual acuity can vary over a wide range among patients with moderate-to-severe glaucoma, but overall, central vision reduction occurs late in the disease. ${ }^{10}$ Mild central and diffuse reduction in fields can also be found in the early stages of glaucoma. As the visual fields and visual acuity decline, patients often note difficulty with glare sensitivity, leaving response times to light and dark adaptations hindered. ${ }^{11}$

In summary, the problems most often experienced by patients with advanced glaucoma are related to ambulation, glare, reading and distance spotting. Low-vision rehabilitation aims to maximize independence in patient's daily lives by addressing these difficulties. The objective of this study is to evaluate the effectiveness of currently available lowvision devices in glaucoma patients who have experienced moderate-to-severe vision loss. Specifically, we are interested in examining whether the quality of life of patients with chronic visual loss can be improved with an improvement in their functional vision through low-vision rehabilitation.

\section{Methods}

\section{Patient population}

The inclusion criteria for the study were the following: a diagnosis of primary or secondary open-angle glaucoma that had been stable for at least 12 months; best-corrected visual acuity in the better seeing eye greater than 20/400 and worse than 20/70; no surgical or laser procedures in the last 6 months; and a retained central visual field of at least $20^{\circ}$ as measured by Humphrey visual field analysis. The exclusion criteria were the following: no access to a telephone; unable to speak English; previously received comprehensive low-vision services; English literacy screening less than fifth grade level; history of stroke with aphasia; other health conditions that would preclude follow-up; unable or unwilling to attend clinical visits; severe hearing impairment that would interfere with participation in telephone questionnaires; history of vitreous hemorrhage, serous or hemorrhagic detachment of the macula or any macular disease such as clinically significant macular edema or cystoid macular edema; and cataract extraction planned within the next 6 months. Both inclusion and exclusion criteria were modeled after the Stelmack et al ${ }^{12}$ study. The study was approved by the human research ethics department at the University of Western Ontario, ON, Canada (REB \#17356). Each patient enrolled in the trial signed consent prior to beginning the study.

\section{Randomization and masking}

Sixteen patients qualified for the study and were assigned randomly, using a computer-generated allocation scheme, to either the low-vision outpatient treatment group or the nonintervention control group. Patients were either assigned a " 1 " or " 2 " denoting treatment or control. The allocation to each group was not dependent on the sample size.

The member of the research team providing training with the devices, and the participants, were aware of the treatment assignments. However, the interviewer administering the Veterans Affairs Low-Vision Visual Functioning Questionnaire 48 (VA LV VFQ-48) was masked to the patient assignment. 


\section{Study design}

Study participants were enrolled in a randomized trial, conducted at one site, St Joseph's Health Care of London, ON, Canada. Participants were selected by reviewing the charts of ophthalmologists Dr Cindy ML Hutnik and Dr Ian McIlraith. Those patients who fit the inclusion and exclusion criteria were interviewed by telephone and invited to a screening examination which entailed detection of bestcorrected visual acuity using the Early Treatment of Diabetic Retinopathy Study (ETDRS) distance visual acuity chart, near-best-corrected visual acuity using the Lighthouse Near Visual Acuity Test, and contrast sensitivity using the Mars Letter Contrast Sensitivity Test. Participants were randomized in either a low-vision outpatient treatment group or a nonintervention control group. The VA LV VFQ-48 ${ }^{13-16}$ was administered by a masked interviewer via telephone.

Those placed in the low-vision outpatient treatment group received additional care, which included a low-vision examination and prescription of low-vision devices, which included binocular telescopes, monocular telescopes, telemicroscopes, magnifiers, portable CCTV and absorptive filters (Table 1). These participants were given low-vision aids for a 4-week span and asked to return for an exit interview to determine which low-vision aids were most beneficial.

The primary outcome measures were the changes in visual reading ability and overall visual ability logit scores on the VA LV VFQ-48 between the low-vision treatment group and nonintervention control group. ${ }^{4}$ Mean changes in three visual ability domains (mobility ability, visual information processing, and visual motor skills) on the VA LV VFQ-48 between the two groups were the secondary outcome measures. A 0.78 increase in logit score between

Table I Low-vision devices prescribed to patients in the treatment group

\begin{tabular}{|c|c|}
\hline $\begin{array}{l}\text { Focus of } \\
\text { the device }\end{array}$ & Device \\
\hline Near vision & Eschenbach Illuminated and Non-Illuminated \\
\hline \multirow[t]{4}{*}{ (reading) } & Handheld Magnifiers $(3.5 \times, 5 \times)$, Illuminated stand \\
\hline & magnifiers (Powerlux 3.5×, 5×; VisoLux + ) \\
\hline & Eschenbach MaxDetail \\
\hline & Electronic handheld magnifiers (Optelec Compact + ) \\
\hline Intermediate & Eschenbach MaxDetail and MaxDetail clip \\
\hline vision & Eschenbach Keplerian telescopes $(2.8 \times, 4.2 \times)$ \\
\hline \multirow[t]{2}{*}{ Long range } & Eschenbach Galilean Telescope $(3 \times)$ \\
\hline & Eschenbach Keplerian Telescope $(2.8 \times, 4.2 \times)$ \\
\hline Absorptive & Cocoon Absorptive fit-over filters (Lemon, \\
\hline filters & Boysenberry, Orange, Hazelnut) \\
\hline
\end{tabular}

Notes: Various low-vision devices and absorptive filters were prescribed to patients randomized to the treatment group. Patients were trained with each device prior to the 4-week outpatient time span. treatment and control groups for visual ability was considered to be the threshold for clinical significance. This correlates to a $31 \%$ improvement in visual ability and an expected accompaniment of a six-line improvement in distance visual acuity on an ETDRS chart. ${ }^{4,5}$ Differences in the primary and secondary outcomes between treatment and control groups were compared using a two-sample $t$-test. Within-group changes were tested by the paired $t$-test. All analyses were two-sided, and a $P$-value less than 0.05 was considered to indicate statistical significance. All analyses were performed using SAS software (version 9; SAS Institute Inc, Cary, NC, USA).

\section{Results}

A total of 16 patients were enrolled in the pilot trial. Ten patients were randomized to the treatment group, and six patients were randomized to the control group. Patients in the treatment group were prescribed and given instructions on how to use all available low-vision aids for the 4-week period, whereas the control group was not prescribed any of the low-vision aids. Patients' quality of life was then assessed using the VA LV VFQ-48. Table 2 shows the outcomes in quality of life (assessed by the VA LV VFQ-48) between the

Table 2 Quality of life mean scores from baseline to 4 weeks $(\mathrm{N}=16)$

\begin{tabular}{|c|c|c|c|c|}
\hline & $\begin{array}{l}\text { Treatment } \\
\text { group }\end{array}$ & $\begin{array}{l}\text { Control } \\
\text { group }\end{array}$ & $\begin{array}{l}\text { Difference } \\
\text { between } \\
\text { treatment } \\
\text { and control }\end{array}$ & $P$-value* \\
\hline \multicolumn{2}{|c|}{ Reading ability } & & & 0.02 \\
\hline Baseline & $1.8 \mathrm{I}(\mathrm{I} .87)$ & $2.60(2.05)$ & & \\
\hline $\begin{array}{l}\text { Change from } \\
\text { baseline }\end{array}$ & $2.48(2.65)$ & $-0.04(0.92)$ & $2.52(2.20)$ & \\
\hline \multicolumn{2}{|c|}{ Mobility ability } & & & 0.29 \\
\hline Baseline & $0.97(1.25)$ & $0.29(2.27)$ & & \\
\hline $\begin{array}{l}\text { Change from } \\
\text { baseline }\end{array}$ & $0.35(1.19)$ & $-0.09(0.34)$ & $0.44(0.97)$ & \\
\hline \multicolumn{2}{|c|}{ Visual information ability } & & & 0.17 \\
\hline Baseline & $1.17(1.65)$ & 0.57 (2.79) & & \\
\hline $\begin{array}{l}\text { Change from } \\
\text { baseline }\end{array}$ & $0.77(1.28)$ & $0.15(0.28)$ & $0.62(1.04)$ & \\
\hline \multicolumn{2}{|c|}{ Visual motor ability } & & & 0.05 \\
\hline Baseline & $0.98(1.19)$ & $0.18(2.5 \mathrm{I})$ & & \\
\hline $\begin{array}{l}\text { Change from } \\
\text { baseline }\end{array}$ & $0.55(0.76)$ & $-0.03(0.3 \mathrm{I})$ & $0.58(0.63)$ & \\
\hline \multicolumn{2}{|c|}{ Overall visual ability } & & & 0.01 \\
\hline Baseline & $1.20(1.22)$ & $0.84(2.17)$ & & \\
\hline $\begin{array}{l}\text { Change from } \\
\text { baseline }\end{array}$ & $0.75(0.79)$ & $-0.03(0.21)$ & $0.78(0.64)$ & \\
\hline
\end{tabular}

Notes: Logit scores and standard deviations of the primary and secondary outcomes are shown. Bolded values indicate a greater than 0.78 logit score improvement. Twosample $t$-tests were performed. $P$-values less than 0.05 were considered significant. 
treatment and control groups, taking into account the primary outcomes (visual reading ability and overall visual ability) and secondary outcomes (mobility ability, visual information ability, and visual motor ability).

Compared to the control patient group, the treatment group reported a significant increase in reading ability and overall visual acuity. The difference in mean changes was $2.52 \pm 2.20$ for reading ability $(P=0.02)$ and $0.78 \pm 0.64$ for overall visual ability $(P=0.01)$. However, no significant changes were demonstrated in mobility ability, visual information ability and visual motor ability.

\section{Discussion}

The goal of this pilot randomized clinical trial was to demonstrate the capabilities of currently available low-vision devices for glaucoma patients with moderate-to-severe vision loss. Previous studies have used similar techniques to determine the effectiveness in ARMD. This is the first such study to examine the effectiveness of a specifically structured rehabilitation process in glaucoma patients. Visual reading ability and overall visual ability were chosen as the primary outcome measures based upon findings in the LOVIT study in which the most frequent goal of the low-vision patients was maximization of reading function. ${ }^{12}$ Furthermore, many low-vision aids currently available are tailored primarily toward reading. ${ }^{12}$ In this study, both reading ability and overall visual ability were included to account for the differences in functional pathology known between glaucoma and ARMD. Significant improvement was seen in the treatment group relative to the control. The increase in logit score demonstrated less difficulty in performing daily tasks such as reading and the use of functional vision.

While reading ability and overall visual ability are important in the quality of life of glaucoma patients, mobility issues and glare are also common complaints. Due to decreased peripheral vision, patients tend to have an increased risk of accidents and falls. Turano et $\mathrm{al}^{17}$ found that patients with glaucoma walked 10\% slower than those without glaucoma. Furthermore, glaucoma patients experienced almost twice as many bumps, stumbles and orientation issues compared to non-glaucomatous patients. ${ }^{17}$ Glare is the cause of visual disability in patients with glaucoma. Nelson et $\mathrm{al}^{11}$ found that upwards of $70 \%$ of patients experienced disabling glare when adapting to different levels of light.

The present study found no significant increase in mobility ability associated with the selected interventions. This is likely due to the fact that the devices used were magnification based with the primary purpose of maximizing central vision while reading. The subjects in the treatment group did show improvements in reading function. This study highlights that the majority of currently available low-vision devices are targeted for patients with primarily central visual loss with virtually no comparable devices available for the glaucoma patients who experience progressive peripheral visual compromise. Although the absorptive lenses used in this study did suggest glare reduction, the data were qualitative. Patients reported that yellow absorptive lenses were more effective at reducing glare and aiding with adaption to varying levels of light compared to orange absorptive lenses.

Although the data presented give insight into the needs of patients with glaucoma and low vision, there are some limitations that should be noted. The first limitation is in regards to the sample size. The small sample size is consistent with a pilot study aimed at assessing feasibility for a future larger study. Further clinical trials with a larger enrollment would help to better understand, refine and give insight into the type of low-vision devices best suited for patients with glaucoma. A notable difference between our study and the Stelmack et $\mathrm{al}^{16}$ study was that we only provided a single training session for the study patients in the treatment group. Stelmack et $\mathrm{al}^{16}$ stated the difficulties behind establishing a low-vision rehabilitation program as an intervention. As our study only investigated the low-vision devices in these patients, the relative effectiveness of the intervention and a potential low-vision rehabilitation program, alone and in combination, was probably underestimated. We predict that a multidisciplinary approach to low-vision rehabilitation would show an even greater improvement in quality of life.

This pilot study examined the effectiveness of currently available low-vision devices in patients with moderate-tosevere glaucoma. A significant increase in reading ability and overall visual ability was determined. This study also demonstrated that currently available low-vision devices primarily address enhancement of central vision with limited benefits to functional activities that rely more upon peripheral vision. This is an important finding when recommending visual aids to glaucoma patients referred for low-vision assessments. These pilot data also highlight that creation of a more comprehensive visual rehabilitation program that employs visual aids for both central and peripheral vision, in addition to consideration of functional ability as a whole, may be useful to optimize independence and quality of life for glaucoma patients with visual loss.

\section{Acknowledgment}

This study was supported in part by research grants from Canadian National Institute for the Blind and Glaucoma Research Society of Canada. 


\section{Disclosure}

The author report no conflicts of interest in this work.

\section{References}

1. US Department of Health and Human Services. Vision research - a national plan: 1999-2003. NIH Publication No 98-4120. Bethesda, MD: National Eye Institute; 1998:117-130.

2. Evans K, Law S, Walt J, Buchholz P, Hansen J. The quality of life impact of peripheral versus central vision loss with a focus on glaucoma versus age-related macular degeneration. Clin Ophthalmol. 2009;3: 433-445.

3. Department of Veterans Affairs. Veterans Health Administration, Blind Rehabilitation Service. Coordinated Services for Blinded Veterans IB 11-59 (revised) P87250. Washington, DC: Department of Veterans Affairs; 1996.

4. Stelmack JA, Tang XC, Reda DJ, et al. The Veterans Affairs Low Vision Intervention Trial (LOVIT): design and methodology. Clin Trials. 2007;4(6):650-660.

5. Stelmack JA, Tang XC, Reda DJ, Rinne S, Mancil RM, Massof RW; LOVIT Study Group. Outcomes of the Veteran Affairs Low Vision Intervention Trial (LOVIT). Arch Ophthalmol. 2008;126(5):608-617.

6. Stelmack JA, Moran D, Dean D, Massof RW. Short- and long-term effects of an intensive inpatient vision rehabilitation program. Arch Phys Med Rehabil. 2007;88(6):691-695.

7. Robinson S. Advanced glaucoma and low vision: evaluation and treatment. In: Schacknow PN, Samples JR, editors. The Glaucoma Book: A Practical, Evidence-Based Approach to Patient Care. New York, NY: Springer; 2010:351-353.
8. McKean-Cowdin R, Varma R, Wu J, Hays RD, Azen SP. Severity of visual field loss and health-related quality of life. Am J Ophthalmol. 2007;143(6):1013-1023.

9. Gutierrez P, Wilson R, Jonson C, et al. Influence of glaucomatous visual field loss on health-related quality of life. Arch Ophthalmol. 1997; 115(6):777-784.

10. Rossetti L, Goni F, Denis P, Bengtsson B, Martinez A, Heijl A. Focusing on glaucoma progression and the clinical importance of progression rate measurement: a review. Eye (Lond). 2010;24 Suppl 1:S1-S7.

11. Nelson $P$, Aspinall $P, O$ 'Brein C. Patients' perception of visual impairment in glaucoma: a pilot study. Br J Ophthalmol. 1999;83(5):546-552.

12. Stelmack JA, Rosenbloom AA, Brenneman CS, Stelmack TR. Patients' perception of the need for low vision devices. J Vis Impair Blind. 2003; 97(9):521-535.

13. Stelmack J, Szlyk J, Stelmack T, et al. Use of Rasch person item map in exploratory data analysis: a clinical perspective. J Rehabil Res Dev. 2004;41(2):233-241.

14. Szlyk JP, Stelmack J, Massof RW, et al. Performance of the Veterans Affairs Low Vision Visual Functioning Questionnaire. $J$ Vis Impair Blind. 2004;98(5):261-275.

15. Stelmack JA, Szlyk JP, Stelmack TR, et al. Psychometric properties of the Veterans Affairs Low-Vision Visual Functioning Questionnaire. Invest Ophthalmol Vis Sci. 2004;45(11):919-928.

16. Stelmack JA, Szlyk JP, Stelmack TR, et al. Measuring outcomes of low vision rehabilitation with the Veterans Affairs Low Vision Visual Functioning Questionnaire (VALV VFQ-48). Invest Ophthalmol Vis Sci. 2006;47(8):3253-3261.

17. Turano KA, Rubin GS, Quigley HA. Mobility performance in glaucoma. Invest Ophthalmol Vis Sci. 1999;40(12):2803-2809.
Clinical Ophthalmology

\section{Publish your work in this journal}

Clinical Ophthalmology is an international, peer-reviewed journal covering all subspecialties within ophthalmology. Key topics include: Optometry; Visual science; Pharmacology and drug therapy in eye diseases; Basic Sciences; Primary and Secondary eye care; Patient Safety and Quality of Care Improvements. This journal is indexed on

Submit your manuscript here: http://www.dovepress.com/clinical-ophthalmology-journal

\section{Dovepress}

PubMed Central and CAS, and is the official journal of The Society of Clinical Ophthalmology (SCO). The manuscript management system is completely online and includes a very quick and fair peer-review system, which is all easy to use. Visit http://www.dovepress.com/ testimonials.php to read real quotes from published authors. 